\title{
Primary chondroma of posterior mediastinum with Horner's syndrome: a case report
}

\author{
Xiaogian $\mathrm{Xu}^{\dagger}$, Xin Li ${ }^{\dagger}$, Fan Ren, Ming Dong, Minghui Liu and Jun Chen ${ }^{*}$ (]
}

\begin{abstract}
Background: Chondroma is a slowly growing, benign cartilaginous tumor which predominantly occurs in long bones of the hands and feet. Primary mediastinal chondroma is rare, especially with Horner's syndrome.

Case presentation: We reported the case of a 31-year-old woman with a posterior mediastinum mass associated with Horner's syndrome. After complete dissection of the mass, a pathological diagnosis of the primary mediastinal chondroma was rendered. The patient has shown no local recurrence or distal disease in a 3.5-year follow-up period.

Conclusions: The preoperative diagnosis of chondroma should combine various examinations for comprehensive evaluation. Complete surgical resection should be the first choice of the treatment due to the risk of malignancy.
\end{abstract}

Keywords: Primary mediastinal mass, Chondroma, Horner's syndrome

\section{Background}

Chondroma is a slowly growing, benign cartilaginous tumor which predominantly occurs in long bones of the hands and feet. Primary mediastinal chondroma is rare. Besides, Horner's syndrome which is characterized by ipsilateral ptosis, miosis, and anhydrosis has been seldom described in such tumors before. Here we report the case of a primary chondroma located in posterior mediastinum which is associated with Horner's syndrome.

\section{Case presentation}

A 31-year-old woman was admitted to our hospital with the chief complaints of anhydrosis on the left upper limb, ipsilateral face, and miosis. These symptoms developed without apparent causes and in the absence of other problems, such as ptosis, enophthalmus, fever, chest pain, breathlessness, cough, expectoration, nausea, or vomiting. Contrast-enhanced computed tomography of the chest revealed a $6.1 \times 5.6 \times 5.5-\mathrm{cm}$, well-circumscribed soft tissue mass in the left posterior mediastinum (Fig. 1). In

\footnotetext{
* Correspondence: huntercj2004@yahoo.com

${ }^{+}$Xiaogian Xu and Xin Li contributed equally to this work.

Department of Lung Cancer Surgery, Tianjin Key Laboratory of Lung Cancer

Metastasis and Tumor Microenvironment, Tianjin Lung Cancer Institute,

Tianjin Medical University General Hospital, Anshan Road No.154, Heping

District, Tianjin 300052, China
}

addition, adjacent intervertebral foramen of thoracic vertebra became larger, and bone destruction of the left second rib can also be seen. Particularly, there was no enlarged lymph node within the mediastinum.

A left posterolateral thoracotomy through the fifth intercostal space was performed. During the surgery, it was found that the mass which was approximately $6 \times$ $5 \times 5 \mathrm{~cm}$ in size arose from the cortex of the second rib and was hard in consistency. Ossification could also be seen within the tumor. We resected the tumor completely and removed partial sclerotin on the surface of the second rib. Histopathologic examination confirmed the diagnosis of chondroma (Fig. 2). Her postoperative course was uneventful. She was discharged without any complication in 12 days after surgery. Follow-up high-resolution computed tomography scans have not detected recurrence 42 months after surgery.

\section{Discussion}

Chondroma is a benign bone tumor that originates from the cartilage tissue. It predominantly occurs in long bones of the hands and feet. It is rare to be found in thoracic cavity, including the lungs, bronchi, and mediastinum [1-3]. Only a few cases of chondroma in the mediastinum have been reported [1-3]. Similar to this case, Zhao et al. reported a giant chondroma originating 


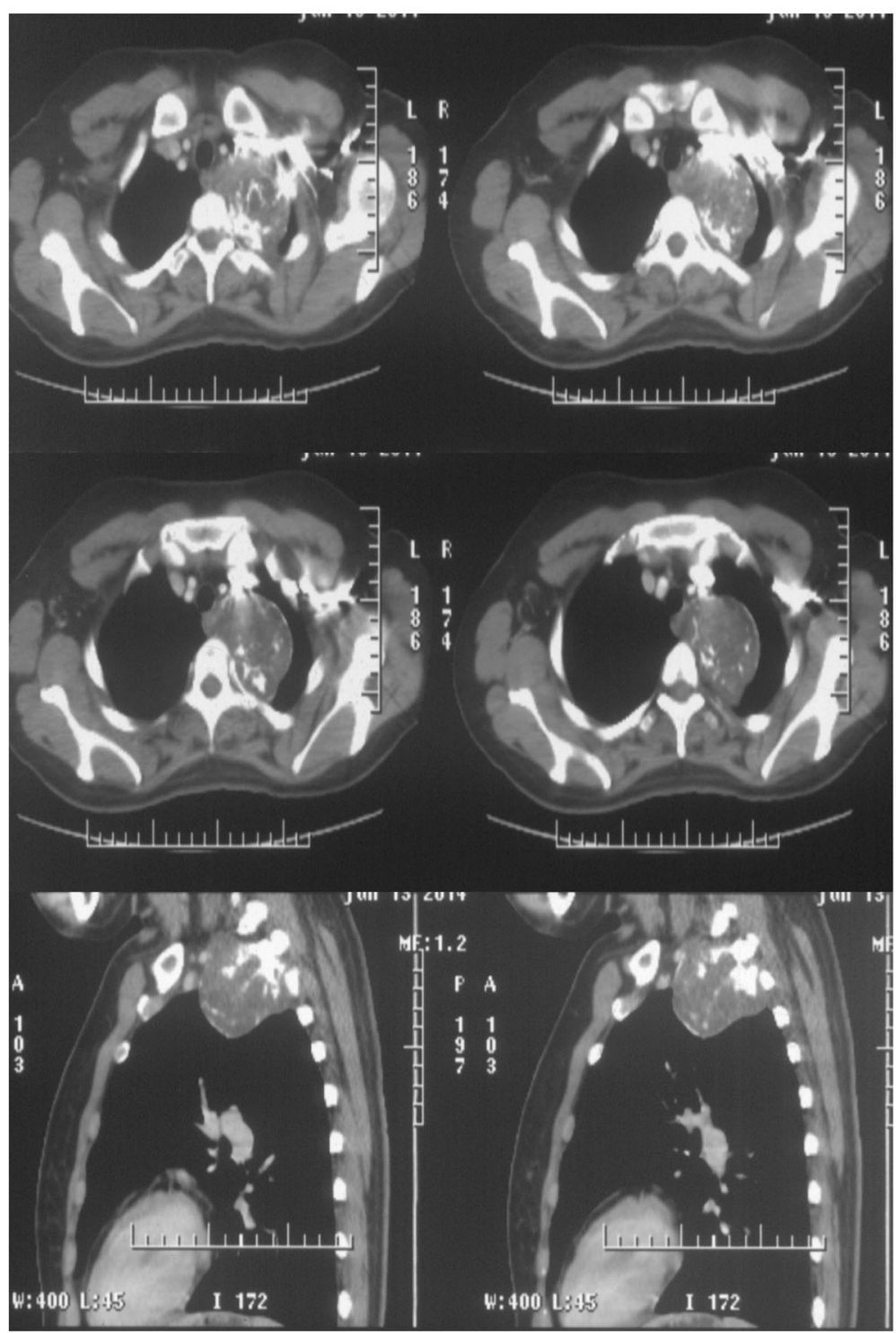

Fig. 1 The contrast-enhanced CT scans of the chest. There was a round, soft tissue density mass in the posterior superior mediastinum. The mass with high-density shadow was related to the left second rib in which soup bubbly appearance and expansion can be found

from the fourth rib on the left [3]. It can occur in any age group, and there is no obvious gender difference. Chondroma in the lungs or mediastinum is usually asymptomatic and discovered incidentally on routine chest radiography. The computed tomography scan of the chest mostly displays a solitary round or oval-shaped nodule or mass with clear borders and even dense in which calcified speckles can be seen. The patient may have symptoms that include chest pain, irritating cough, or neurological abnormalities due to compression or direct invasion of surrounding mediastinal structures. Macroscopically, the tumor is gray-white translucent, and the lobes can be seen in the section. Microscopically, the tumor is composed of well-differentiated cartilage tissue and surrounded by cartilage matrix. In this case, the contrast-enhanced computed tomography revealed a round and soft tissue density mass in posterior superior mediastinum in which nodular and lined high-density shadow can be seen. And the tumor was related to the left second rib in which soup bubbly appearance and expansion can be found. The patient had Horner's syndrome including symptoms like left ptosis, miosis, enophthalmos, and facial anhydrosis as a result of the compression of the cervical sympathetic nerve.

\section{Conclusion}

The preoperative diagnosis of chondroma should combine various examinations for comprehensive evaluation. 


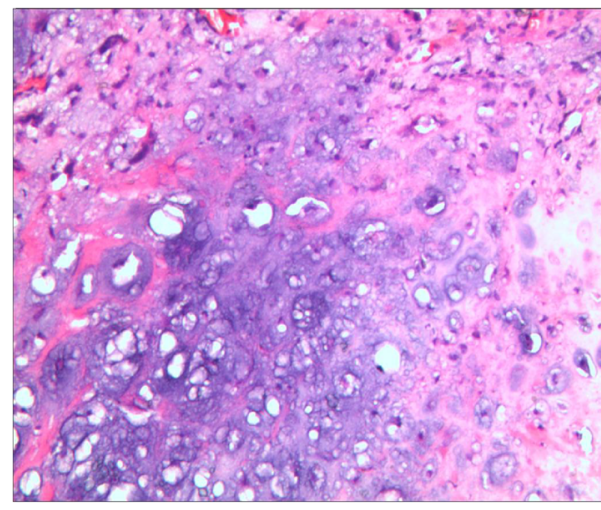

$\times 10$

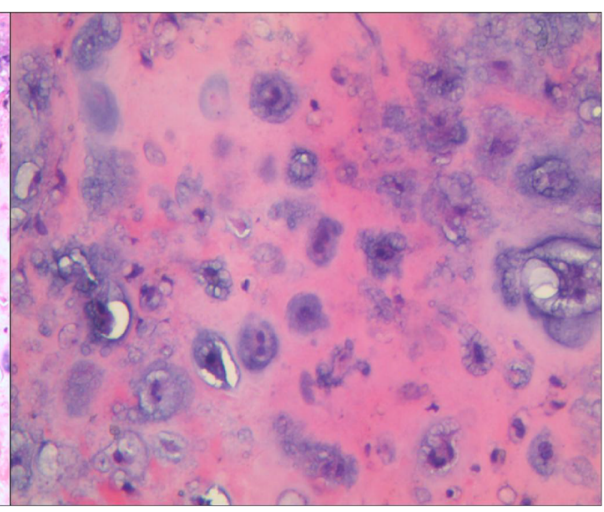

$\times 20$

Fig. 2 Pathological characteristics. The pathologic examination showed the chondroma with dense chondrocytes and active growth by H\&E staining

At the same time, we should differentiate it with lung hamartoma, tuberculosis, and other diseases. Complete surgical resection should be the first choice of the treatment due to the risk of malignancy [4]. We usually choose partial lung resection or lobectomy for pulmonary chondroma and tumor resection for mediastinal chondroma [5]. Surgical treatment is effective for chondroma, and the tumor is rare to relapse and metastasize.

\section{Abbreviation}

CT: Computed tomography

\section{Funding}

This work was financially supported by grants from the National Natural Science Foundation of China $(81773207,61573251)$, the Science and Technology Support Key Program of Tianjin (17YFZCSY00840), the Tianjin Key Project of Natural Science Foundation (16JCZDJC34200), and the Special support program for High Tech Leader \& Team of Tianjin. The funders had no role in the study design, data collection and analysis, decision to publish, or preparation of the manuscript.

\section{Availability of data and materials}

All available data are presented in the case.

\section{Authors' contributions}

$X X, X L$, and $J C$ wrote this manuscript and analyzed all data. $X X, X L, F R, M D$, and $M L$ provided medical care for the patients and collected the data. JC revised the article. All authors read and approved the final manuscript.

\section{Ethics approval and consent to participate}

This case was approved by the ethics committee of our institution (Tianjin Medical University General Hospital).

\section{Consent for publication}

Written informed consent was obtained from the patient for the publication of this case report and the accompanying images. A copy of the consent form is available for review by the Editor-in-Chief of this journal.

\section{Competing interests}

The authors declare that they have no competing interests.

\section{Publisher's note}

Springer Nature remains neutral with regard to jurisdictional claims in published maps and institutional affiliations.
Received: 10 July 2018 Accepted: 9 October 2018

Published online: 17 October 2018

References

1. Widdowson DJ, Lewis-Jones HG. A large soft-tissue chondroma arising from the posterior mediastinum. Clin Radiol. 1988:39(3):333-5.

2. Shrivastava V, Vundavalli S, Smith D, et al. A chondroma of the anterior mediastinum. Clin Radiol. 2006:61(12):1065-6.

3. Zhao XG, Chen G, Chen XF. Giant periosteal chondroma of the rib associated with mediastinum deviation. Ann Thorac Surg. 2012;94(3):1014.

4. Salminen US, Halttunen P, Taskinen $E$, et al. Recurrence and malignant transformation of endotracheal chondroma. Ann Thorac Surg. 1990;49(5): 830-2.

5. Ludwig C, Zeitoun M, Stoelben E. Video-assisted thoracoscopic resection of pulmonary lesions. Eur J Surg Oncol. 2004;30(10):1118-22.

Ready to submit your research? Choose BMC and benefit from:

- fast, convenient online submission

- thorough peer review by experienced researchers in your field

- rapid publication on acceptance

- support for research data, including large and complex data types

- gold Open Access which fosters wider collaboration and increased citations

- maximum visibility for your research: over $100 \mathrm{M}$ website views per year

At $\mathrm{BMC}$, research is always in progress.

Learn more biomedcentral.com/submissions 